\title{
Correction to: Automatic Detection of Shoreline Change by Geographical Information System (GIS) and Remote Sensing in the Seyhan Delta, Turkey
}

\author{
Dilara Ciritci ${ }^{1} \cdot$ Tarık Türk $^{1}$ (D)
}

Published online: 10 June 2020

(C) Indian Society of Remote Sensing 2020

\section{Correction to: Journal of the Indian Society of Remote Sensing (February 2019) 47(2):233-243 https://doi.org/10.1007/s12524-019- 00947-1}

The correct title of the article should read as "Automatic Detection of Shoreline Change by Geographical Information System (GIS) and Remote Sensing in the Seyhan Delta, Turkey"

In page 233 , in the abstract, the third line should read as "In this study, it is aimed to reveal the shoreline change occurring in the Seyhan Delta by using satellite images and GIS-based analyses."

In page 234 , in the second paragraph, the first line should read as "In this study, it is aimed to detect the shoreline change occurring in the Seyhan delta by different methods and to reveal the measures to be taken by remote sensing and GIS-based analyses".

In page 234, the study area section should read as:

In this study, the vicinity of Seyhan Delta was chosen as the study area. This area is one of the key biodiversity area and consists of the region where the Seyhan River and Tarsus Stream are poured into the Mediterranean and Tuzla and Akyatan lakes. Akyatan is Turkey's largest lagoon. On 15 April 1998, it has been included in the RAMSAR Contract List and it has been committed at the international level, where the ecological character of the area will be preserved. Tuzla lagoon was declared as a Natural Protected Area in 1997. At the same time, this lagoon is an important bird area and internationally important wetland

The original article can be found online at https:// doi.org/10.1007/s12524-019-00947-1.

Tarık Türk

tarikturk@gmail.com

1 Department of Geomatics Engineering, Faculty of Engineering, Cumhuriyet University, 58140 Sivas, Turkey ecosystems according to international criteria. The boundary of the study area is the approximately $40-\mathrm{km}$ long coastal area between Kazanli District to the west of the Seyhan River and Tuzla township to the east.

In page 234, in the Materials and Methods section, the first line should read as "In this study, for the purpose of detecting the temporal change occurring on the coasts of the Seyhan delta that is located in Adana province, black and white (Binary) images in which sea and land borders of the region were more clear were obtained by the image rating method using Landsat 5 TM satellite images covering a period of 27 years between 1984 and 2011."

In page 235, the correct Fig. 1 is provided as follows:

In page 235, under the heading Data used, in the second paragraph, the third line and fourth line should read as "An attempt to find the images of June or the images of the months that were close to June was made in the selection of images for the other years determined to be used in the analysis of change. In the region that was put under protection after the RAMSAR convention signed in 1998 (Akyatan logoon added to the RAMSAR protected area list in 1998 and Tuzla lagoon declared as a natural protected area in 1997), the images of month June of 2003 and July of 2006 were used to prevent changes on the shore and to examine whether studies achieved their purposes"

The correct figure and caption for Fig. 4 should read as follows:

In page 239, under the Results and Discussion section, the first line should read as "The annual changes of the shorelines were calculated using the SCE, EPR, and LRR methods in $95 \%$ confidence interval. In the analysis, 814 transects were formed on a total of $40-\mathrm{km}$ shoreline of the Seyhan delta, including approximately $20 \mathrm{~km}$ on the left shore and approximately $20 \mathrm{~km}$ on the right shore, at intervals of $50 \mathrm{~m}$ (Fig. 4)."

The correct Fig. 6 is provided as follows:

In page 242, under the heading conclusions, in the first paragraph, the first line and second line should read as "In 


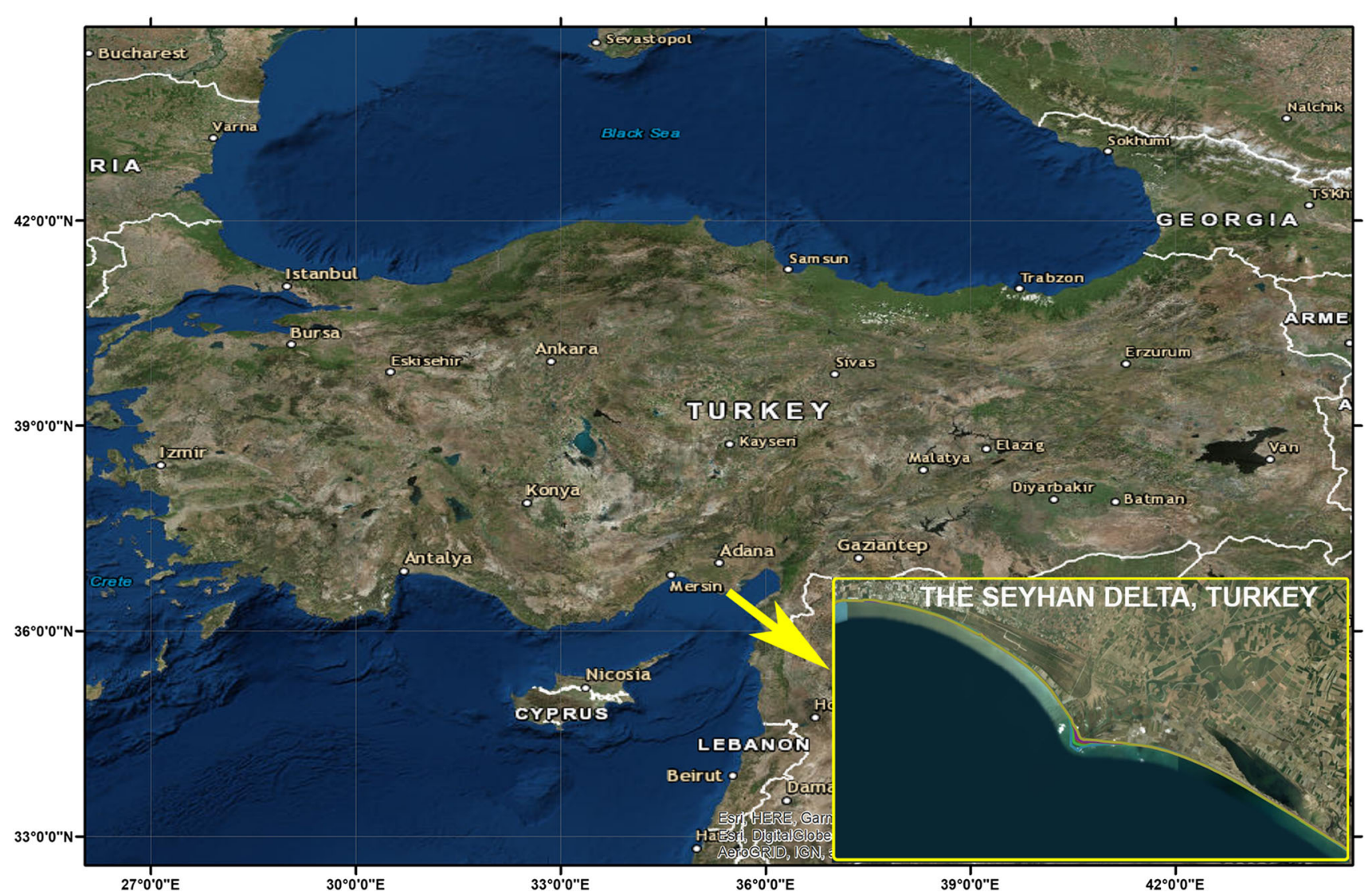

Fig. 1 Study area

this study, the current situation was revealed by detecting the changes taking place in the coastal areas in the Seyhan delta by GIS and remote sensing methods, and a number of solution proposals were presented for the problems caused by shoreline changes. In this context, the Seyhan delta area was divided into three regions."

In the second paragraph, the second and third lines should read as "Seyhan delta (Akyatan lagoon and Tuzla lagoon) is among the most important wetlands of the 


\section{THE SHORELINE, BASELINE AND TRANSECT ACCORDING TO REGIONS}
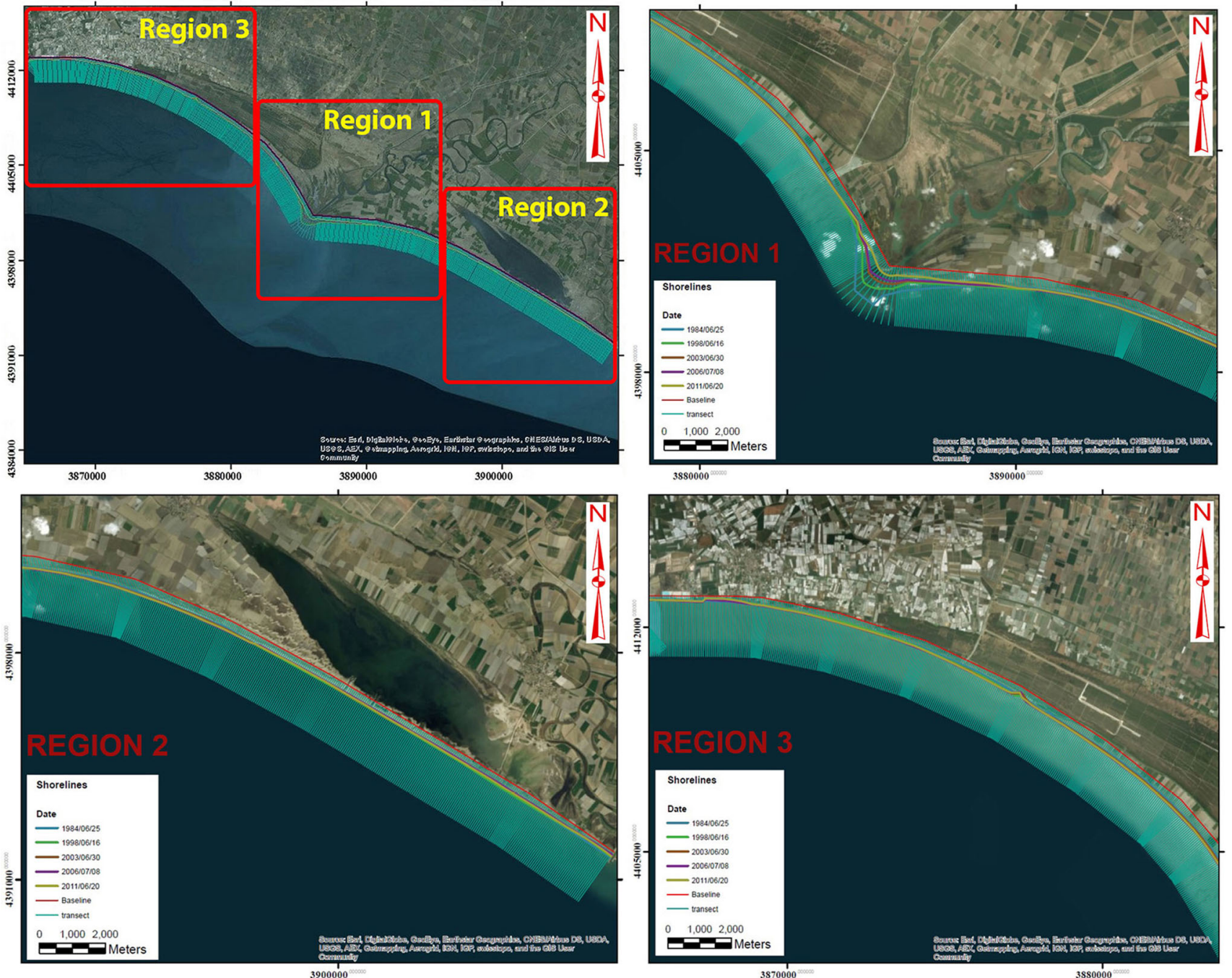

Fig. 4 Shoreline, baseline and transect according to regions in the Seyhan delta, Turkey

ecological, economic and cultural aspects. Moreover, Akyatan lagoon in the delta is one of 14 wetlands put under protection in Turkey by the RAMSAR convention."
The third paragraph should read as "One of the most important threats on the Seyhan Delta is that some small marsh and seasonal wetland habitats near the Tuzla and Akyatan lakes have dried up. Nevertheless, in recent years, 


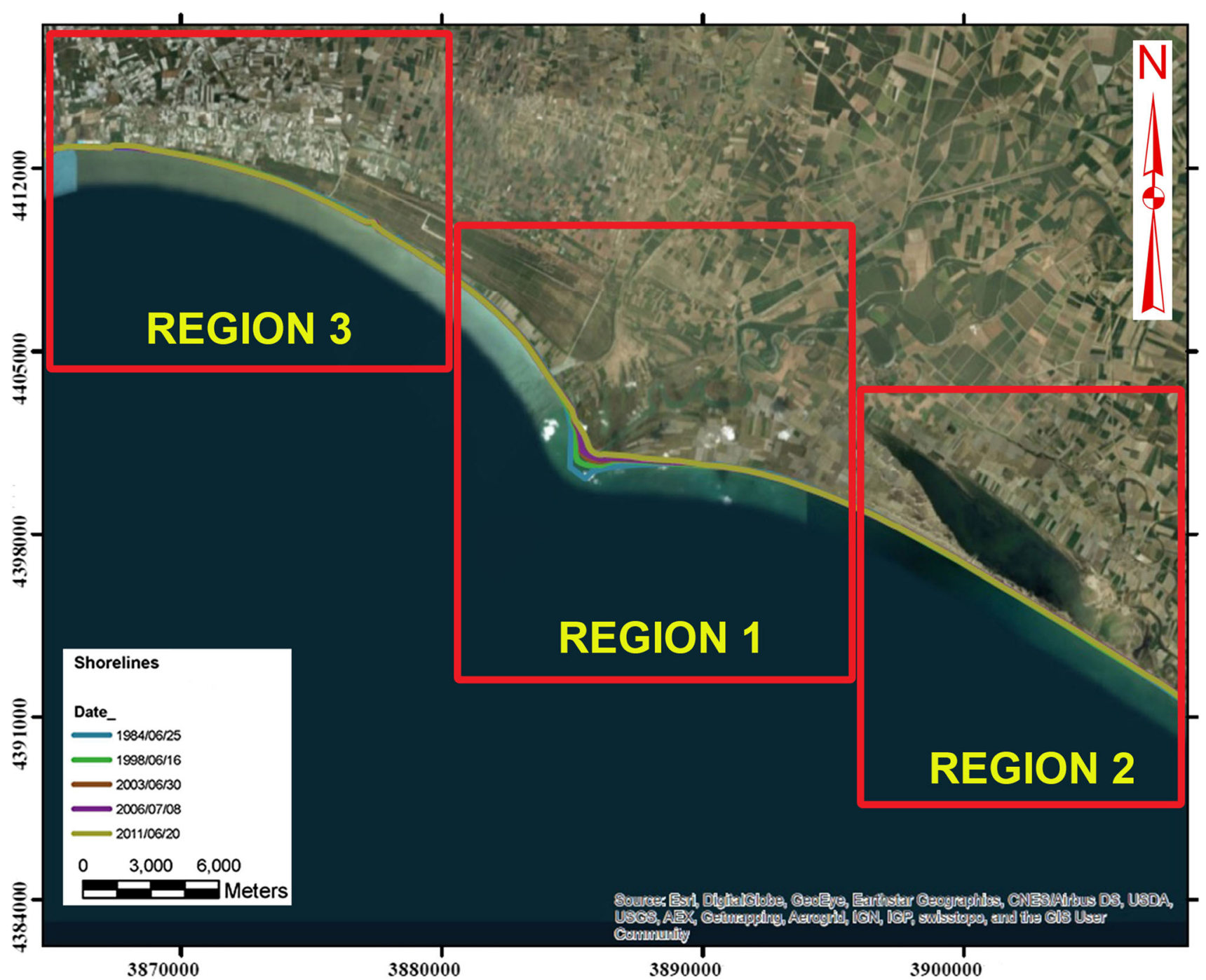

Fig. 6 Shoreline temporal change map of the Seyhan Delta, Turkey

groundwater used in agricultural fields in the key biodiversity areas has caused the water balance and dune structure to deteriorate. For these reasons, measures to be taken in such an important area should be carried out with the entire ecosystem in mind" 